\title{
Structural, Elemental and Molecular Characterization of Normal And Osteoarthritic Human Articular Cartilage
}

\author{
Çayır $\mathrm{T}^{* 1}$, Akaltun $\mathrm{Y}^{2}$, Memişoğlu $\mathrm{K}^{3}$ and Gündoğdu $\mathrm{O}^{1}$
}

${ }^{1}$ Department of Biomedical Engineering, University of Kocaeli, Kocaeli, İzmit 41000, Turkey

${ }^{2}$ Department of Electrical and Electronic Engineering, University of Erzincan, Erzincan 24000, Turkey

${ }^{3}$ Department of Orthopedics and Traumatology, University of Kocaeli , Kocaeli, İzmit 41000, Turkey

*Corresponding author: Çayır T, Department of Biomedical Engineering, University of Kocaeli, Kocaeli, İzmit 41000, Turkey, Tel: +90 262 30302218, E-mail: tubacyr@hotmail.com

Citation: Çayır T, Akaltun Y, Memişoğlu K, Gündoğdu O (2017) Periodic Micro Hole Texturing with Metal Assisted Chemical Etching for Solar Cell Applications: Dependence of Etch Rate on Orientation. J Mater Sci Nanotechnol 5(1): 104. doi: 10.15744/2348-9812.5.104

Received Date: March 17, 2017 Accepted Date: May 30, 2017 Published Date: June 02, 2017

\begin{abstract}
The articular cartilage overlying the bone consists of a network of collagen fibres. This network is essential to cartilage integrity, usually suffering damage in degenerative joint diseases such as osteoarthritis. We have been applying a number of techniques to study the bone-cartilage interface and of changes occurring in this with disease. The bone-cartilage samples with disease were investigated for their structural, elemental and molecular properties. The bone-cartilage samples with disease were characterized by scanning electron microscopy- energy dispersive X-ray spectroscopy (SEM-EDX) and Fourier Transform infrared spectroscopy (FTIR) and Fourier transform (FT) Raman spectroscopy. The energy dispersive X-ray (EDX) analysis confirmed nearly stoichiometric samples. The Raman spectra made it possible to monitor the changes in the main bone constituents: the mineral component with the apatite band at $960 \mathrm{~cm}^{-1}$, the organic component with the collagen amide III band at $1268 \mathrm{~cm}^{-1}$.Present results have been obtained on sections of bone not displaying evidence of an osteoarthritic lesion and can be used as a baseline against which diseased bone can be compared.
\end{abstract}

Keywords: Bone-cartilage; Raman; SEM-EDX; FTIR

\section{Introduction}

Bone is a complex tissue which integrates two basic components, organic (matrix) and inorganic (mineral) material [1]. Its high strength and fracture toughness is achieved by a unique architecture of organic and inorganic phases [2-4]. It contains nano sized mineral platelets (essentially carbonated hydroxyapatite), protein (mainly collagen type I), and water [3,5,6]. The matrix makes up $30-40 \%$ of the total bone material and consists of collagen and other non-collagenous protein sand lipids [6]. Around 85$90 \%$ of the total protein content is made up by collagen fibrils. The mineral substance is mainly a carbonated form of crystalline calcium phosphate with a total percentage in bone material of 60-70\% [7]. Therefore, because of the structural complexity of bone, its healing is an extremely complex process which has been under extensive investigation for many years [8]. Articular cartilage has an extracellular matrix composed primarily of water, type II collagen fibrils and proteoglycans [9]. Histologically, articular cartilage has unique variations in its morphological structure and molecular composition across its tissue depth, which is commonly considered to comprise three sub-tissue zones based on local fibril orientation [10]. These three zones are (a) the superficial zone (SZ) where the collagen is oriented parallel to the articular surface, (b) the transitional zone (TZ) where the collagen is oriented rather randomly, and (c) the radial zone (RZ) where the collagen is oriented mainly perpendicular to the articular surface. The critical role of the collagen matrix in cartilage is to preserve the tissue integrity where any alteration of the collagen microstructure due to tissue lesions will inevitably disrupt the molecular environment, consequently modifying the mechanical properties of the tissue.

Osteoarthritis is a joint disease that affects most people in the middle and elderly ages. It's slow. The cartilage structure of the joint due to aging changes. Being overweight, fractures in cartilage due to falling or some other mechanical trauma, followed by damage to the menus and ligaments, narrowing of the joint space and new bone formation.

$\mathrm{OA}$ is the most common form of arthritis, with an average prevalence of $10-12 \%$ in various populations. It is the most common cause of disability and pain caused by musculoskeletal system in geriatric patients. OA affects $10 \%$ of the population in 55 ages; at the age of 75, this rate exceeds 50\%. Prevalence and the severity of the disease are increasing with age. Age is thestrongest sign of 
OA in all joint regions. OA affects both genders, while the ratio of female to male is somewhat between 1.5: 1 and 4: 1 changing Table 1.

\begin{tabular}{|c|c|}
\hline Osteoarthritis & Aging \\
\hline Cartilage hydration $\uparrow$ & Cartilage hydration $\uparrow$ \\
\hline Proteoglycan concentration $\downarrow$ & Proteoglycan concentration $\leftrightarrow$ \\
\hline Collagen density $\downarrow$ & Collagen density $\leftrightarrow$ \\
\hline Chondrocyte proliferation $\uparrow$ & Chondrocyte proliferation $\leftrightarrow$ \\
\hline Metabolic activity $\uparrow$ & Metabolic activity $\leftrightarrow$ \\
\hline \multicolumn{2}{|c|}{ Table 1: Relationship between Aging and Osteoarthritis }
\end{tabular}

Several microscopic imaging techniques have been used to study the load-induced deformation of the collagen matrix in articular cartilage. For example, microscopic MRI (IMRI) has been successfully used to image the modification of the tissue morphology in intact tissue blocks based on the proton signals in water molecules [11]. Scanning electron microscopy can directly visualize the effect of mechanical loading on the organization of the collagen fibrils in cartilage matrix [12]. The technique of Fourier transform infrared (FT-IR) spectroscopy is a powerful tool to study the previously described changes in degenerative cartilage at the molecular level. Raman analysis is sensitive to molecular orientation, and discerning between orientation and compositional contribution is crucial as bone is comprised of mineralized collagen fibres with alternating orientation within successive lamellae. The capability of Raman microspectroscopic analysis to distinguish between structural and chemical changes in bone were reported, by exploiting the dual influence of composition and structure with in the sample on the Raman signal $[13,14]$.

Two human femoral head cartilage specimens from the surgery of humans are reported in this paper. While one of the samples is of a osteoarthritic cartilage the other is a healthy cartilage. The healthy cartilage was due to a femoral head fracture. Prior to the sample analysis, there were no fixations, embedding or surface processing. This work is an effort to characterize the healthy and diseased bone-cartilage by using a combination of techniques such as scanning electron microscopy-energy dispersive X-ray spectroscopy (SEM-EDX), FT-IR and Raman spectroscopy. The aim of this study is to make comparison of structural, elemental and molecular properties of healthy and diseased bone-cartilage samples.

\section{Materials and Methods}

Human femoral heads from total hip replacement procedures were used, due to surgicalintervention in responsse to a degenerative joint disease. The femoral heads were sourced from the department of Orthopedics and Traumatologyat Kocaeli University(Turkey). Using a water-cooled diamond saw(Isomet 1000 Precision ) severalsections at certain thicknesses were cut perpendicular to the articular surface from the superior aspect of the femoral head with thicknesses ranging from $200 \mu \mathrm{m}$ to $300 \mu \mathrm{m}$. These sections were subsequently soaked in distilled water to remove any bone marrow and loose particulate matter. Morphological and elementel investigations were conducted on a scanning electron microscopy (Zeiss Supra 50 VP model SEM-EDX) with an acceleration voltage of $25 \mathrm{kV}$.Absorbance FT-IR spectra were obtained using a Thermo Scientific spectrometer in the range of $4000-400 \mathrm{~cm}^{-1}$ using $\mathrm{KBr}$ pellets at room temperature. The resolution was $2 \mathrm{~cm}^{-1}$, and the number of scans was 30 .

An inViaReflex ${ }^{\mathrm{Tm}}$ and an inViaQontor Raman microscope (Renishaw plc, Wotton-under-Edge, UK) were used. The spectrometers were configured with a diode laser excitation $\left(785 \mathrm{~nm}\right.$ ) with the laser power of $300 \mathrm{~mW}$, a $600 \mathrm{~g} \mathrm{~mm}^{-1}$ grating (Reflex) / a $1200 \mathrm{~g}$ $\mathrm{mm}^{-1}$ grating (Qontor), a motorized XY stage and a charge coupled device (CCD) detector. A line-shaped laser output was focused onto the sample through a microscope using a $\times 20$ microscope objective.

\section{Result}

The surface morphology and elemental analysis of the healthy and diseased femoral heads were characterised by scanning electron microscopy and enery dispersive X-Ray spectrometer. Figure 1 shows the SEM images of the osteoarthritic femoral head cartilage sample and healthy cartilage (femoral head fracture) sample.

Figure 1 shows that femoral head fracture cartilage have a smooth surface structure. The cartilage surface contains the presence of lacuna, chondrocytes and the chondroblasts structures. For the osteoarthritic femoral head cartilage, the level of surface deformation increased. Because of deterioration cartilage surface has occurred as the disease progresses. Consequently, the surface properties significantly, changed due to with cause deformation and diseases.

Figure 2 shows the EDX data of the osteoarthritic femoral head cartilage sample and healthy cartilage (femoral head fracture) sample. Figure 2 shows that healthy and diseased cartilage samples have elements such as Ca, P, S, C, etc. It is evident that healthy bone cartilage sample has more amount of elements such as calcium, phosphorus, etc., than the diseased cartilage. 

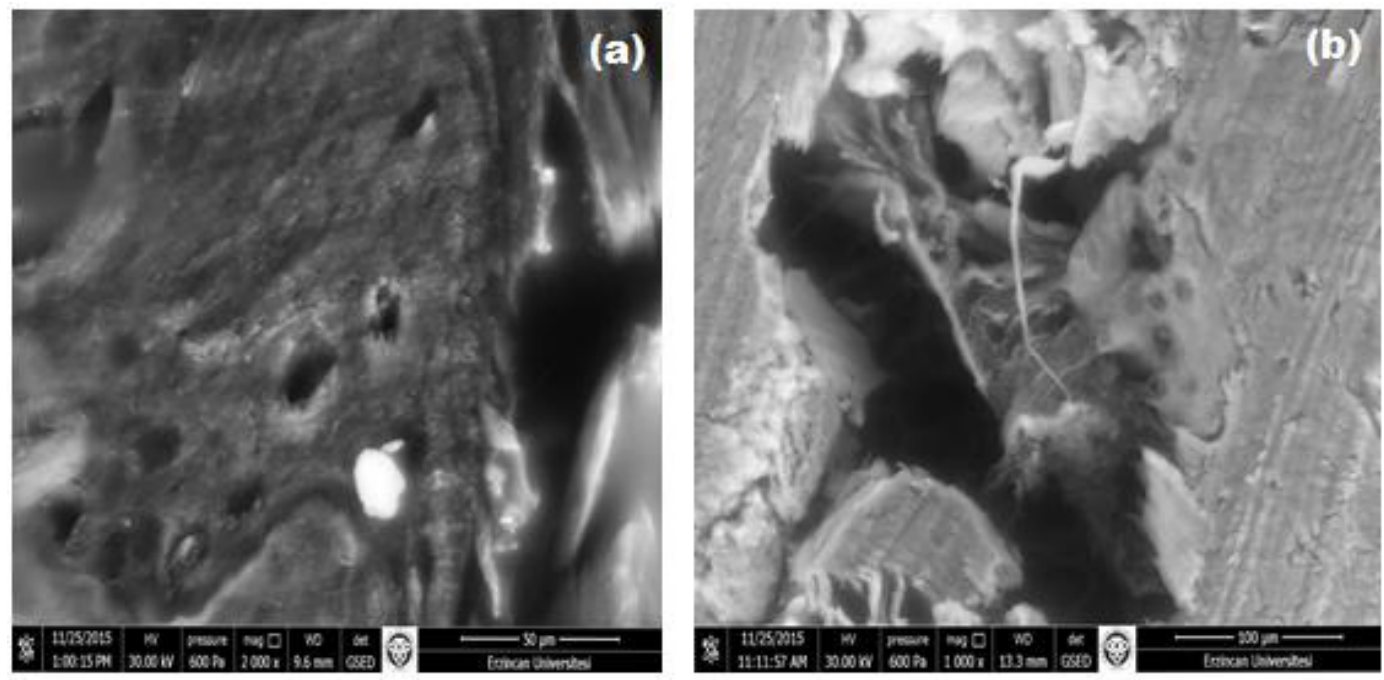

Figure 1: SEM images of (a) healthy and (b) diseased cartilage samples
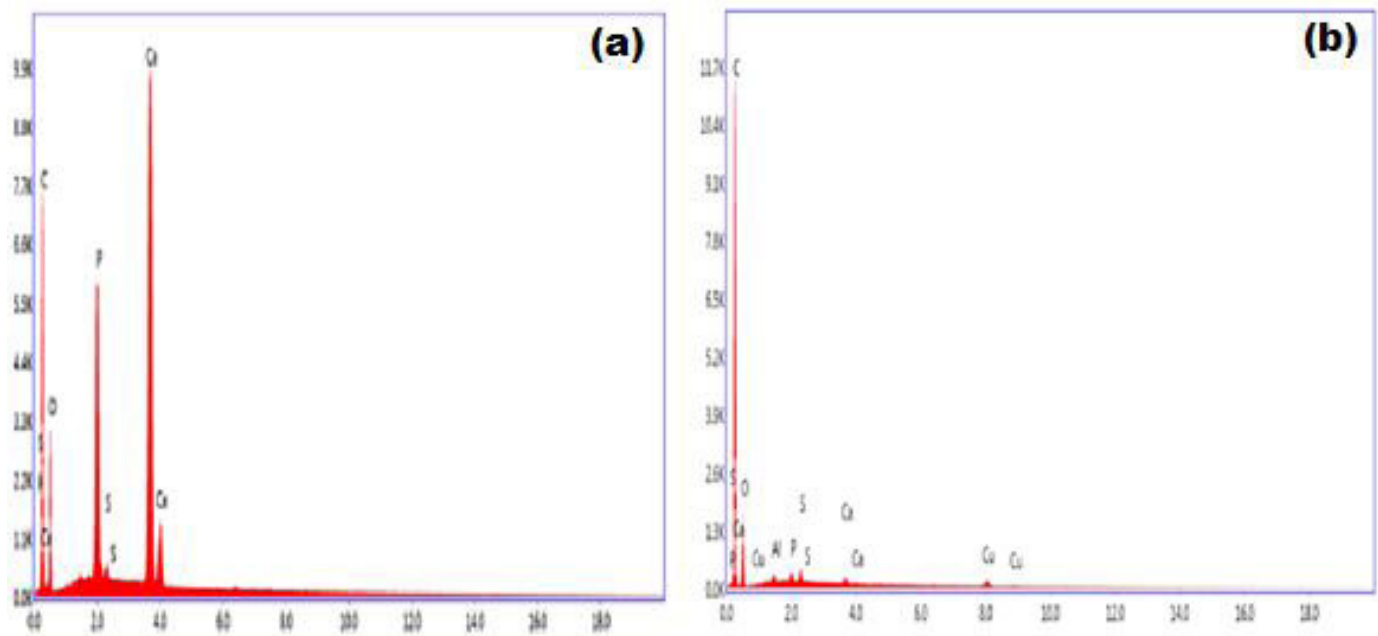

Figure 2: EDX data healthy and diseased cartilage samples

Figure 3 shows the RAMAN spectra of the osteoarthritic femoral head cartilage sample and healthy cartilage (femoral head fracture). Surface StreamLine images were obtained in an area of $773.9 \mu \mathrm{m}$ x $248.5 \mu \mathrm{m}$, using $90 \mathrm{~mW}$ laser power, 4 seconds/line acquisition time, and a $7.1 \mu \mathrm{m}$ step size.
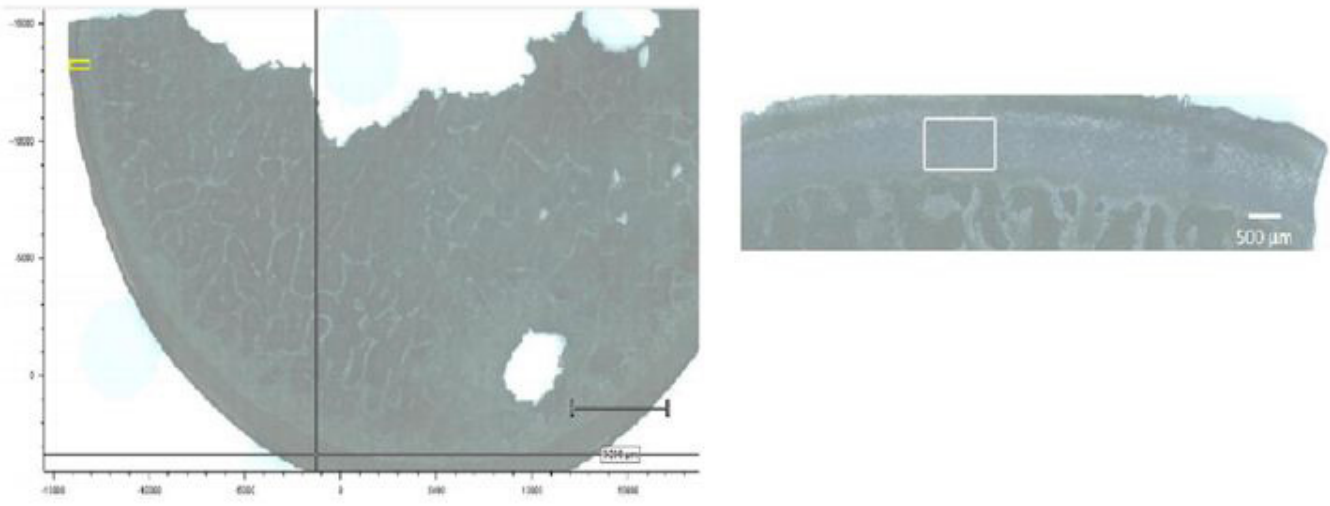

Figure 3: White light image of healthy and diseased cartilage. The yellow box indicates the Surface Stream Line imaged area/ The white box indicates Surface Stream Line analysed area

The human osteoarthritic cartilage tissue section is shown in Figure 4. The data collection points are indicated by stars and numbered as: 1-) the cartilage, 2-) bone-cartilage interface, 3-) bone section, close to the interface and 4-) bone middle section. 

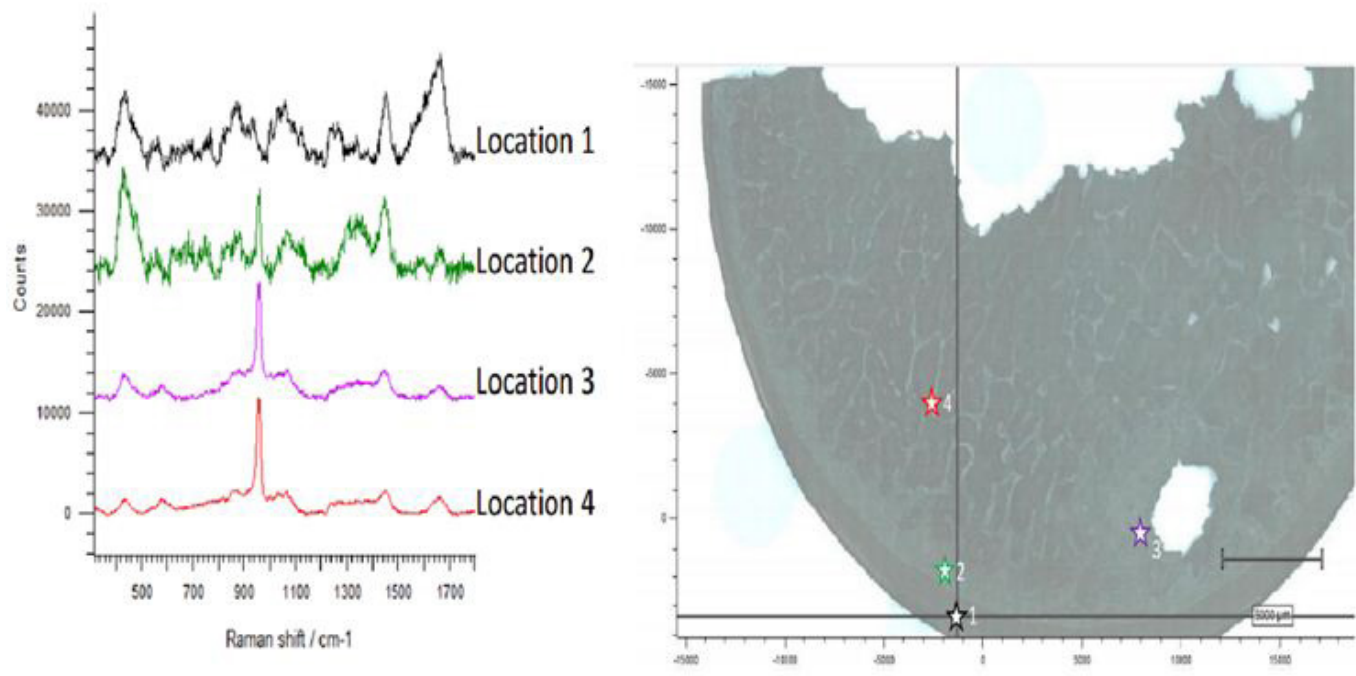

Figure 4: White light image of a healthy cartilage section. The stars indicate where point spectra were acquired

Figure 5 shows the Raman spectra from the four different regions that are indicated in Figure 4 . The prominent bands are labeled. The $v_{1}$ phosphate stretching vibration at $960 \mathrm{~cm}^{-1}$ is the strongest marker for bone mineral. The broader bands are assigned to amide III $\left(\sim 1239\right.$ and $\left.1268 \mathrm{~cm}^{-1}\right)$, the C-H bending mode $\left(\sim 1450 \mathrm{~cm}^{-1}\right)$, and amide I $\left(\sim 1668 \mathrm{~cm}^{-1}\right)$. The amide I at $\sim 1668 \mathrm{~cm}^{-1}$, and amide III $\sim 1239$ and $1268 \mathrm{~cm}^{-1}$ peaks are mainly due to the presence of collagen, while the C-H bending band at $\sim 1450 \mathrm{~cm}^{-1}$ is present in both collagenous and noncollagenous organic moieties. When the spectra are compared Number 1 through Number 4 , from the interface to the bone middle section, the relative intensity of the phosphate stretching vibration is increased as a result of increase in the mineral content. Whereas, the relative intensity of the band vibrations that are responsible from organic content of the tissue section is decreased. The osteoarthritic femoral head cartilage sample was analyzed by Live Track StreamLine and the image of the sample illustrated in Figure 6.

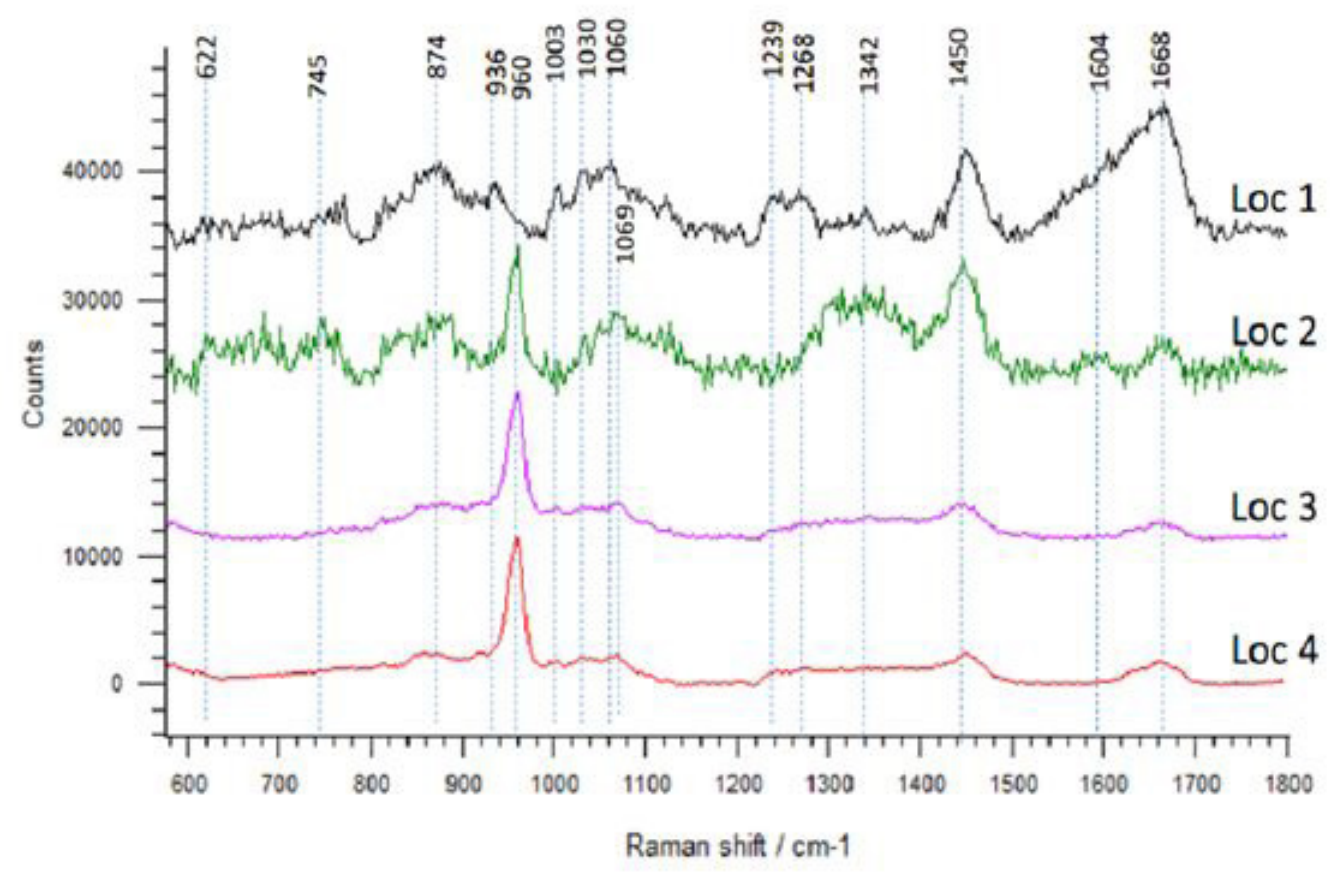

Figure 5: Raman spectra acquired from the locations marked by the stars in Figure 4

The spectrum displays mainly signals that are coming from the protein content, such as tryptophan, C-C protein, proline, hydroxyproline $\left(874 \mathrm{~cm}^{-1}\right)$, phenylalanine $\left(1003 \mathrm{~cm}^{-1}\right.$ and $\left.1030 \mathrm{~cm}^{-1}\right)$, amide III (collagen type I, $1239 \mathrm{~cm}^{-1}$ and $\left.1268 \mathrm{~cm}^{-1}\right), \mathrm{CH}$ from protein $\left(1450 \mathrm{~cm}^{-1}\right)$ and amide I (collagen type I, $\left.1668 \mathrm{~cm}^{-1}\right)$. Besides protein signals, the glycosaminoglycan and hydroxyapatite $\left(\mathrm{PO}_{4}^{3-}\right)$ vibrations are also evident in the spectrum. The hydroxyapatite signal scores are relatively low values compared with the bone tissue sections. 

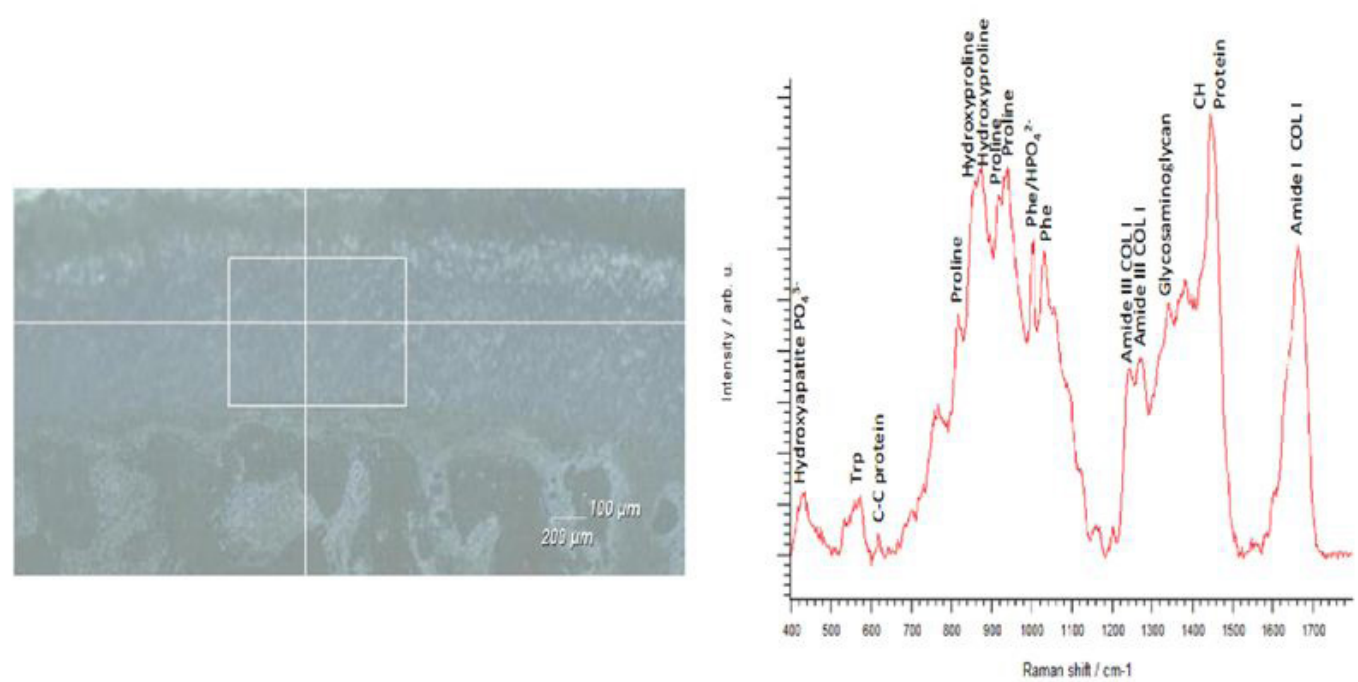

Figure 6: White lightimage of the osteoarthritic femoral head cartilage sample, as seen in Figure 3. The white box indicates the Surface Stream Line analysed area. At the cross hair position a single spectrum is acquired. An example spectrum from the cross hair position shown in Figure 6

Figure 7,8 shows FT-IR absorbance spectra of the samples. Two samples were characterized by use of FTIR spectrometry (Thermo Scientific, Erzincan, Turkey) as described. Data were collected in the absorption mode between 4000 and $400 \mathrm{~cm}^{-1}$, with resolution $2 \mathrm{~cm}^{-1}$. We used previous assignments of absorption bands. For healthy cartilage regarding carbonated apatite $\left[\mathrm{CA} ; \mathrm{Ca}{ }_{10}(\mathrm{PO})_{6}(\mathrm{OH})\right.$ $\left.\left(\mathrm{CO}_{3}\right)_{\mathrm{y}}\right]$, the $v_{1}$ and $v_{3} \mathrm{P} \mathrm{O}$ stretching vibration modes were measured at $723 \mathrm{~cm}^{-1}$ and $1163 \mathrm{~cm}^{-1}$ respectively, and the $\mathrm{O}-\mathrm{P}-\mathrm{O} v_{4}$ bending mode corresponded to the doublet at $531 \mathrm{~cm}^{-1}$. Regarding $\mathrm{m}-\mathrm{CPPD}, \mathrm{O}-\mathrm{P}-\mathrm{O}$ bending was recorded at 514 and $500 \mathrm{~cm}^{-1}$. Amid I, Amid II and Amid III infrared bands were measured at $1740 \mathrm{~cm}^{-1}, 1464-1377 \mathrm{~cm}^{-1}$ and $1201 \mathrm{~cm}^{-1}$ respectively. These values change for diseased cartilage. For healthy cartilage regarding carbonated apatite $\left[\mathrm{CA} ; \mathrm{Ca}_{10}\left(\mathrm{PO}_{4}\right)_{6}(\mathrm{OH})_{\mathrm{x}}\left(\mathrm{CO}_{3}\right)_{\mathrm{y}}\right], v_{3} \mathrm{P}-\mathrm{O}$ stretching vibration mode was measured at $1026 \mathrm{~cm}^{-1}$, and the $\mathrm{O}-\mathrm{P}-\mathrm{O} v_{4}$ bending mode corresponded to the doublet at $517 \mathrm{~cm}^{-1}$. Amid $\mathrm{I}$, Amid II and Amid III infrared bands were measured at $1747-1646 \mathrm{~cm}^{-1}, 1540-1457 \mathrm{~cm}^{-1}$ and $1338-1200 \mathrm{~cm}^{-1}$ respectively.

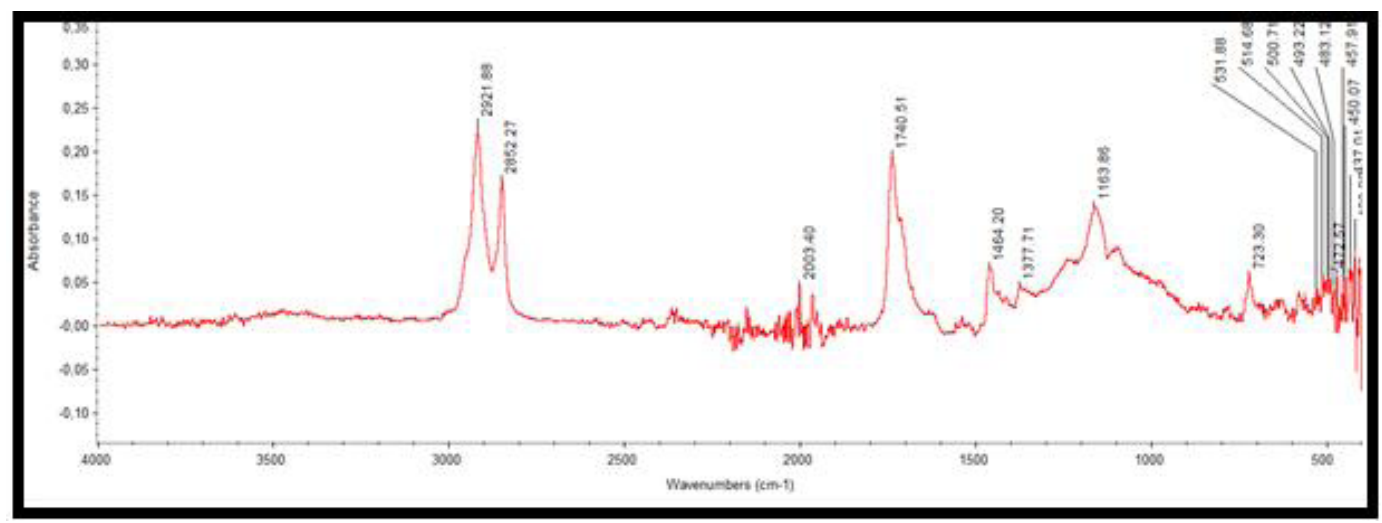

Figure 7: FT-IR spectra of healthy cartilage samples

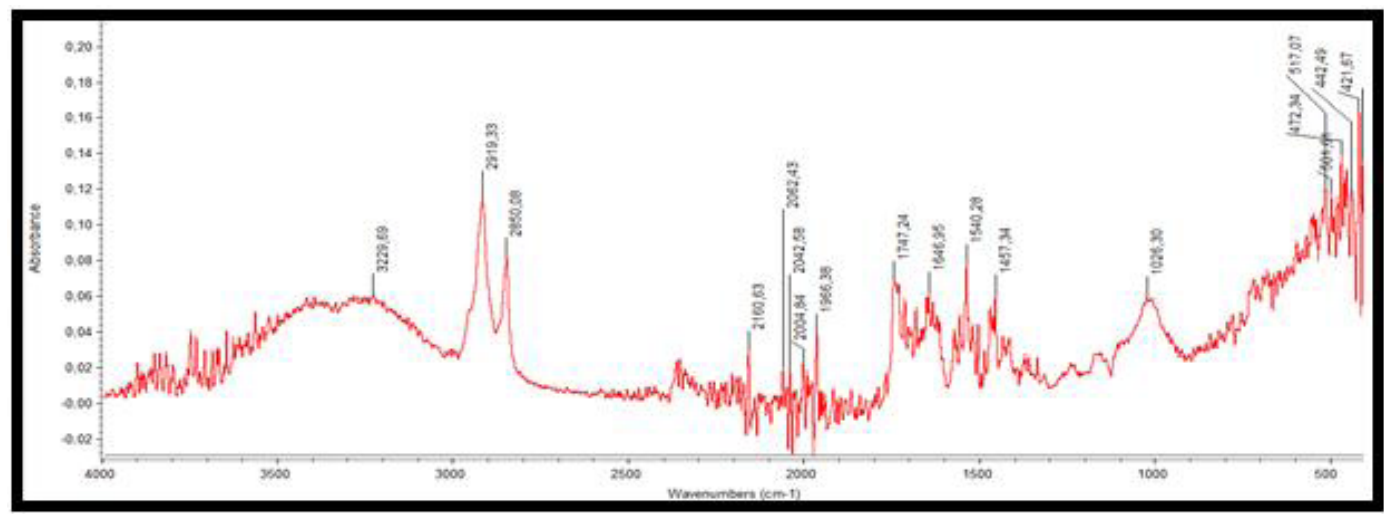

Figure 8: FT-IR spectra of diseased cartilage samples 


\section{Conclusions}

We used SEM-EDX, FT-IR and RAMAN spectroscopy to characterize the healthy and diseased bone-cartilage samples. SEM technique is a useful tool to investigate the localization of specific proteins within the cartilaginous matrix and also within mineralized tissue. The technique provides ease of visualization of the location of specific collagens within cartilage as well as mineralized tissue. Due to the clear and definitive labeling that can be seen when using backscattered electron imaging, the technique of SEM can be used to quantify amounts of different collagens present in cartilage and mineralized tissue.SEM results show that the surface properties changed significantly due to deformation and diseases. It was found quantity of basic elements of the diseaded bone-cartilage sample decreased. RAMAN spectrum displays mainly signals that are coming from the protein content, such as tryptophan, C-C protein, proline, hydroxyproline. The Raman spectra from the four different regions that are indicated. The prominent bands are labeled. The $v_{1}$ phosphate stretching vibration at $960 \mathrm{~cm}^{-1}$ is the strongest marker for bone mineral. The mineral and organic structures obtained in cartilage, interface, bone and middle bone sections differ. The results obtained FT-IR analysis through also suggests disruption of bone cartilage structure. The results reveal that there are structural, elemental and molecular differences in healthy and diseased cartilages.

\section{References}

1. R Wojnar, in: A Ochsner, W Ahmed (2010) Bone and Cartilage - its Structure and Physical Properties, in Biomechanics of Hard Tissues: Modeling, Testing, and Materials, Wiley-VCH Verlag Gmb H\&Co. KgaA, Weinheim, Chapter 1.

2. K Kaviyarasu, N Geetha, K Kanimozhi, C MariaMagdalane, S Sivaranjani et.al (2017) In vitro cytotoxicity effect and antibacterial performance of human lung epithelial cells A549 activity of Zinc oxide doped TiO2 nanocrystals:Investigation of bio-medical application by chemical method. Mater Sci Eng C Mater Biol Appl 74: 325-33.

3. P Fratzl, R Weinkamer (2007) Nature’s hierarchical materials. Prog Mater Sci 52: 1263-334.

4. DB Burr (2002) Perspective: The contribution of the organic matrix to bone's material properties. Bone $31: 8-11$.

5. EM Rivera-Munoz in R Fazel-Rezai (2011) Hydroxyapatite-Based Materials,Synthesis and Characterization, Biomed Eng-Front Chal In Tech, Chapter 4.

6. S Weiner, HD Wagner (1998) THE MATERIAL BONE: Structure-Mechanical Function Relations Annu Rev Mater Sci 28: 271-98.

7. G Boivin, PJ Meunier (2003) The mineralization of bone tissue: a forgotten dimension in osteoporosis research. OsteoporosInt 14: 19-24.

8. CB Lopes, MT Pacheco, L Silveira, J Duarte, MCCangussu, AL Pinhero et al. (2007) The effect of the association of NIR laser therapy BMPs, and guided bone regeneration on tibial fractures treated with wire osteosynthesis: Raman spectroscopy study. J Photochem Photobiol B 89: 125-30.

9. A. Maroudas (1975) Biophysical chemistry of cartilaginous tissues with special reference to solute and fluid transport. Biorheology 12: 233-48.

10. K Kaviyarasu, A Raja, Prem Anand Devarajan (2013) Structural elucidation and spectral characterizations of Co3O4 nanoflakes. Spectrochim Acta Part A: Mole Biomolec Spectro 114: 586-91.

11. HA Alhadlaq, Y Xia (2005) Modifications of orientational dependence of microscopic magnetic resonance imaging T(2) anisotropy in compressed articular cartilage. J Magn Reson Imaging 22: 665-73.

12. C Glaser, R Putz (2002) Functional anatomy of articular cartilage under compressive loading quantitative aspects of global, local and zonal reactions of the collagenous network with respect to the surface integrity. Osteoarthritis Cartilage 10: 83-99.

13. M Kazanci, P Roschger, EP Paschalis, K Klaushofer (2006) Bone osteonal tissues by Raman spectral mapping: orientation-composition. J Struct Biol 156: 489496.

14. G Leroy, G Penel, N Leroy, E Bres (2002) Human tooth enamel: a Raman polarized approach. Appl Spectrosc 56: 1030-4.

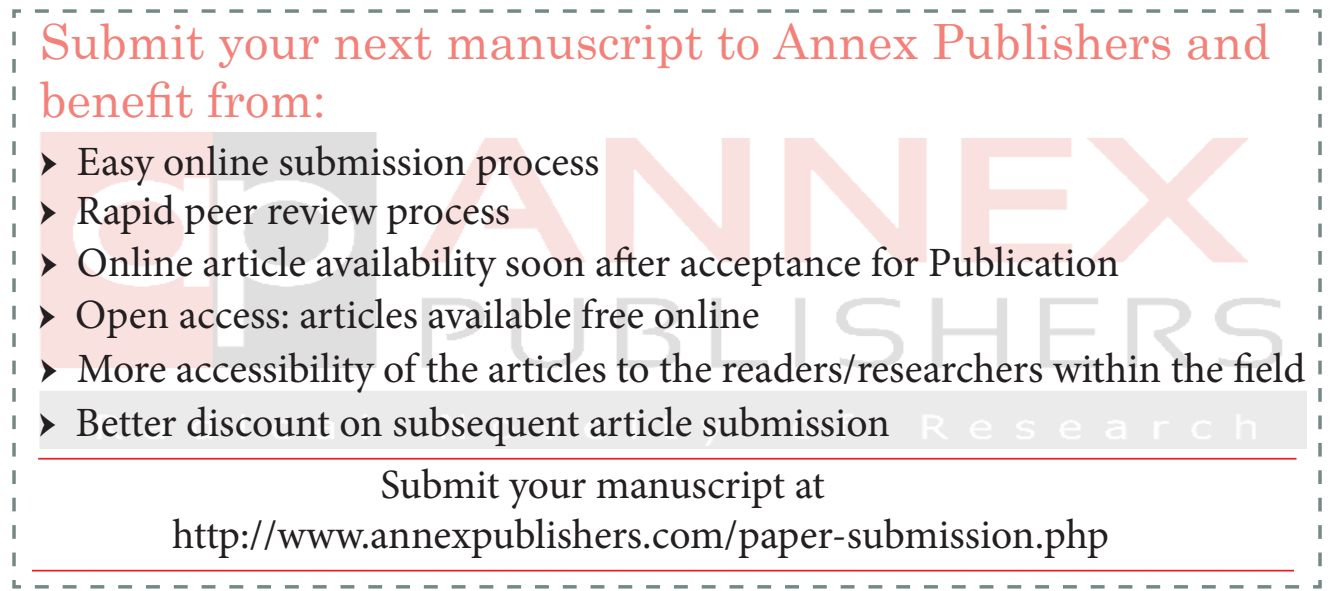

